\title{
THE VASCULAR CONTRIBUTION TO OSTEOGENESIS
}

\section{Changes in the Growth Cartilage Caused by Experimentally Induced Ischaemia}

\author{
J. Trueta, Oxford, England, and V. P. Amato, Sliema, Malta \\ From the Nuffield Orthopaedic Centre, Oxford.
}

In the two preceding papers of this series the vascular pattern close to the growth cartilage, and the relationship between vessels, cartilage cells and calcification, were studied under normal, or experimentally unaltered, conditions (Trueta and Morgan 1960, Trueta and Little 1960) and the findings were used as a control for the experimental work to be described in this and succeeding papers.

This study reports the changes in the epiphysial cartilage caused by the suppression of its blood supply. The changes caused by the interruption of the epiphysial blood flow will be described first and a description of the changes produced by interrupting the metaphysial circulation will follow.

\section{METHOD}

Forty six-weeks-old chinchilla rabbits, averaging 1,100 grammes in weight, were used. Operations were done on both tibiae under general anaesthesia (Nembutal and ether). In the right tibia a small hole was drilled on the medial side of the tibial epiphysis, avoiding so far as possible any direct damage to the growth plate. A small flat spatula was introduced through the drill hole until it reached approximately to the centre of the epiphysis when it was moved in a circular sweep in a plane parallel to the epiphysial cartilage. The cavity thus produced was packed with a strip of polythene film to prevent revascularisation. The lateral side of the epiphysis was left undisturbed to serve as a control.

In the left tibia a similar technique was used but the block was placed on the metaphysial side of the growth cartilage and at a sufficient distance to prevent direct damage to it. All the forty rabbits were subjected to this procedure and out of the eighty tibiae operated upon seventy-eight were available for analysis: one tibia became infected and another fractured. The investigation proceeded in the following way:

Group $A$-Twelve rabbits were killed at intervals of 1, 2, 3, 4, 5, 6, 9, 12, 15, 18, 21 and 24 days after operation in order to study the changes in the epiphysial cartilage caused by ischaemia. Group B-A second operation was performed on all the remaining rabbits to remove the polythene sheath at intervals of 2,4 and 8 days after the first operation. The rabbits were killed and injected at intervals of 2, 4, 6, 12, 16, 18, 21 and 24 days after the second operation in order to study the revascularisation that occurred.

\section{RESULTS}

INTERRUPTION OF THE EPIPHYSIAL BLOOD SUPPLY

The first changes occurred in the epiphysis itself. As early as the second day after operation many trabeculae were seen to be dead, with empty lacunae. By superimposing the stained histological preparations on the unstained sections it was seen that the dead trabeculae corresponded exactly to areas deprived of vascularity. These two changes - that is, the signs of bone death and the presence or absence of blood vessels-when seen in the terminal bone plate covering the growth cartilage, proved that the blood supply of the epiphysial plate had been cut off.

When revascularisation was allowed to occur the evidence was still available, for the dead trabeculae could be seen enveloped by new bone (Fig. 1). The thick sections showed 


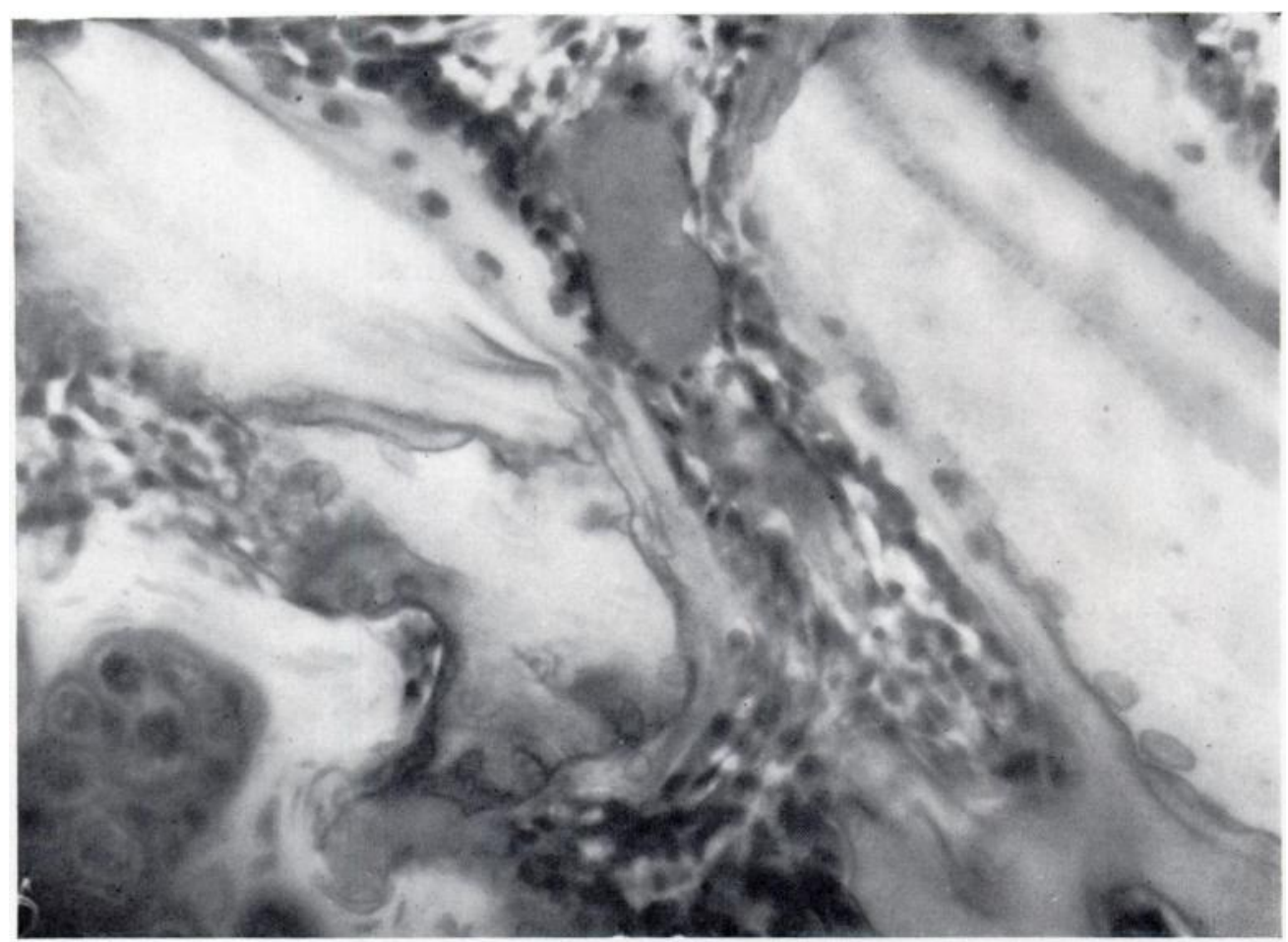

Fig. 1

New bone being laid down over dead trabeculae of the epiphysial bone plate, showing that revascularisation has occurred. $(\times 320$. $)$

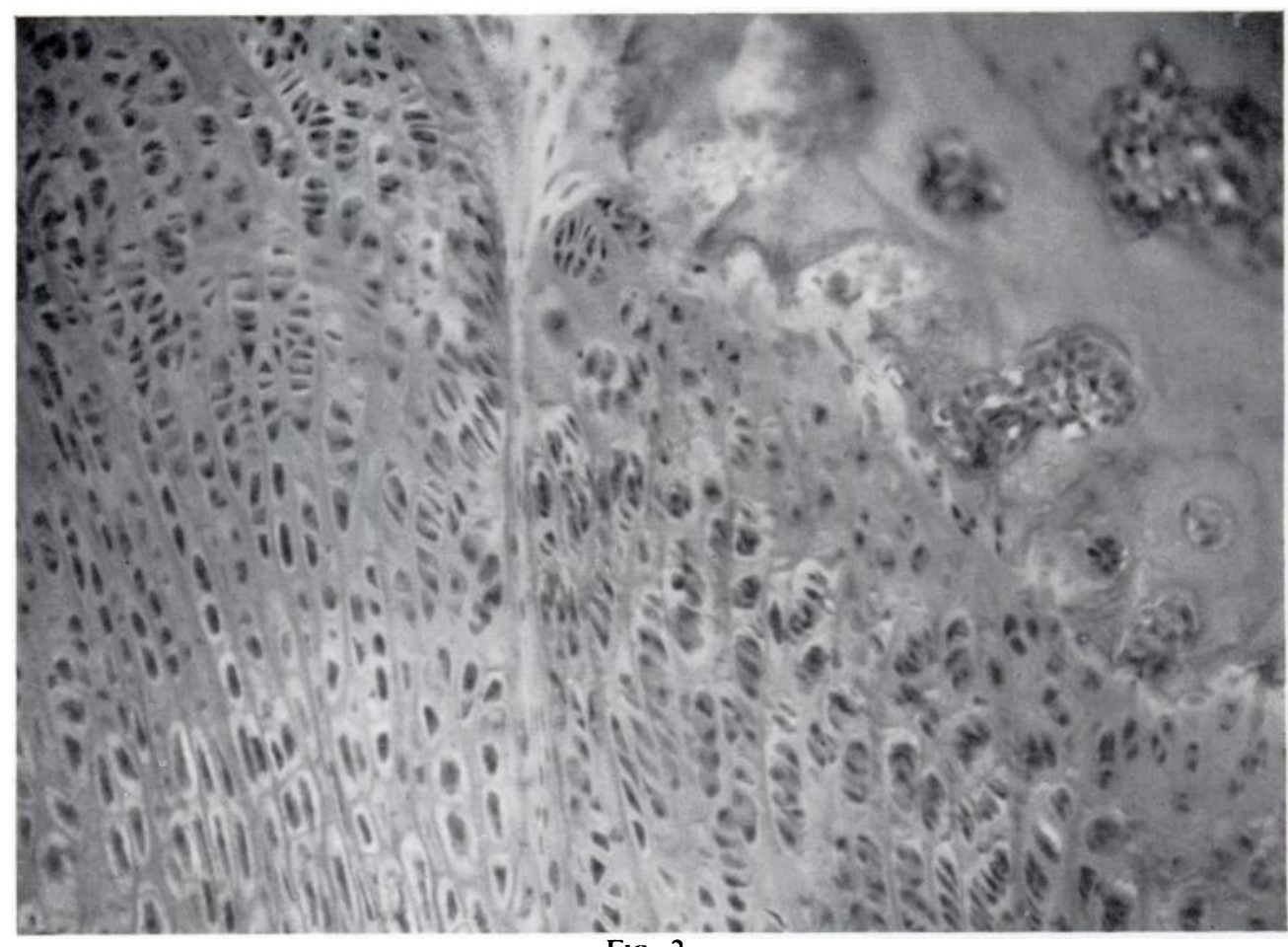

FIG. 2

Local damage to the epiphysial growth cartilage caused by interrupting the blood flow through the epiphysial vessels. The bone is dead but the blood vessels have returned and are actively burying the dead trabeculae. $(\times 85$. 


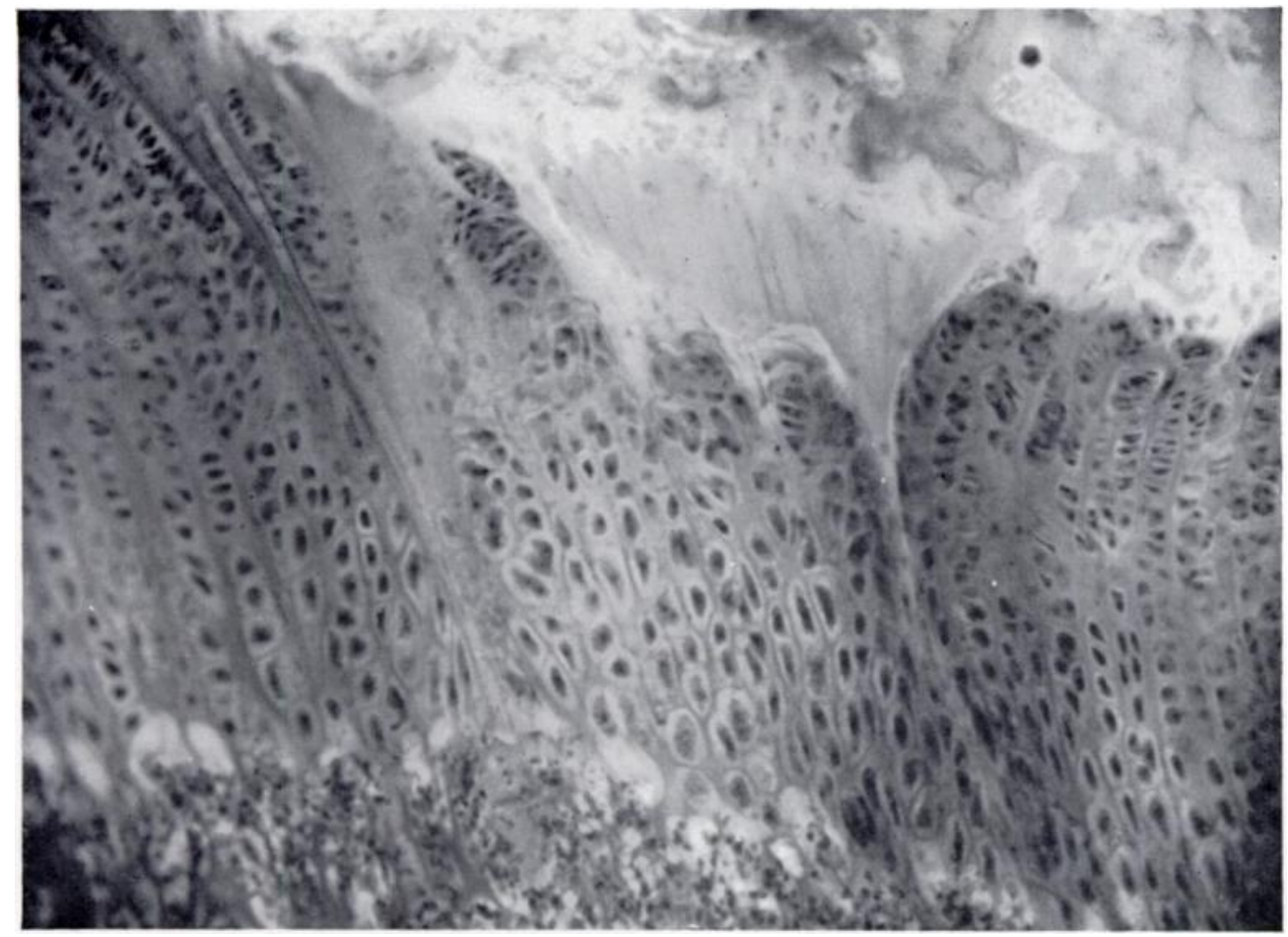

Fig. 3

Damage to cell columns by the suppression of the epiphysial blood supply. $(.75$.)

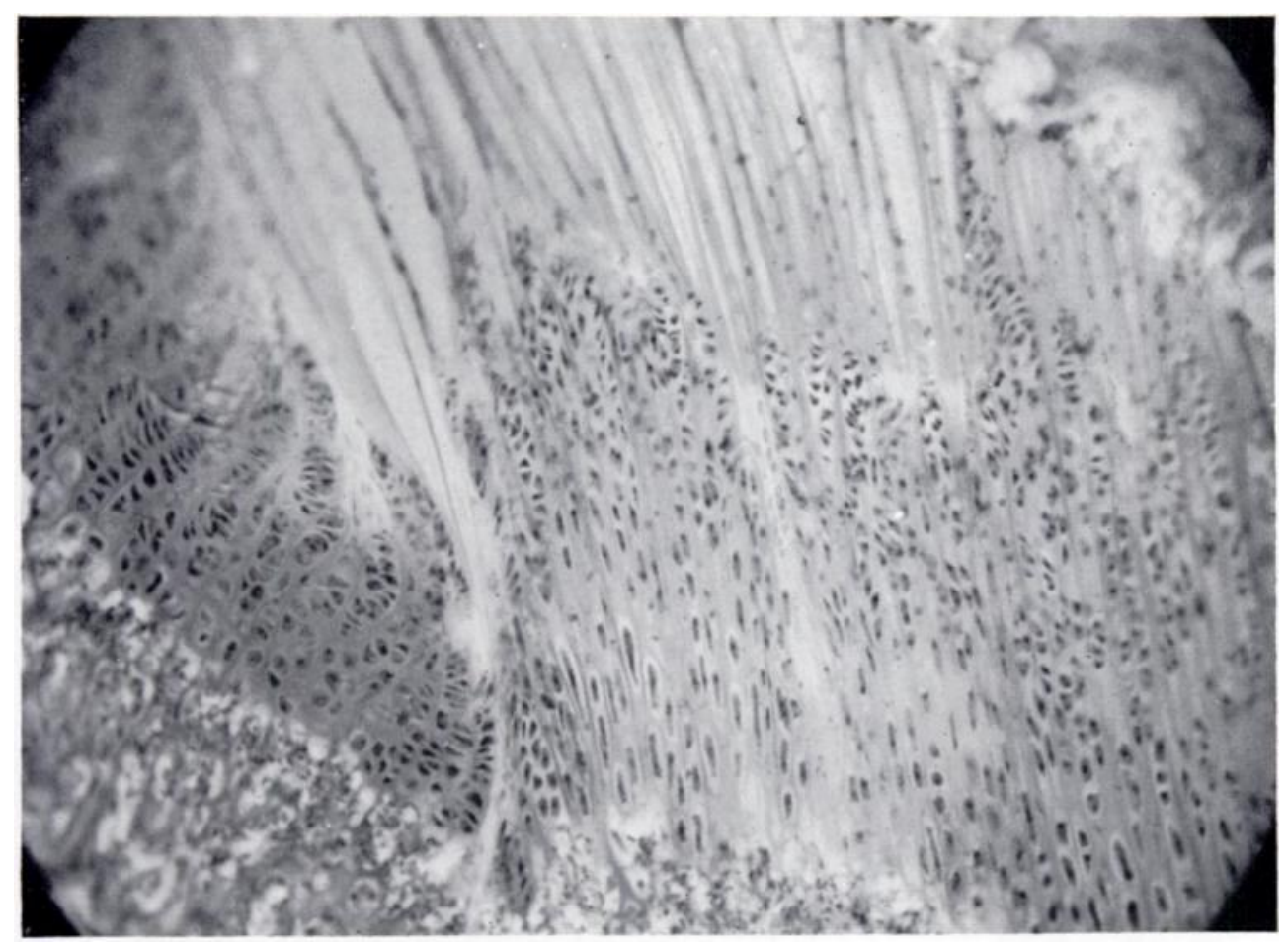

Fig. 4

The infarcted portion of the epiphysial growth cartilage is being pulled out by the growth of the healthy cells in the nearby columns. $(\times 55$. 
that the new blood supply in most instances was entering the epiphysis from the site of the operation. The newly established circulation was seen to correspond exactly with the areas where new bone was being laid down on the scaffolding of dead trabeculae in the terminal bone plate.

When the operation scar was placed far from the plate and the penetration was not deep enough into the central portion of the epiphysis there were only moderate changes attributable to interference with the circulation. The terminal bone plate appeared normal and all the vessels filled with dye. A transient widening of the growth plate was seen sometimes when it was compared with the undisturbed side of the plate. This widening was due both to a moderate increase in the number of cells of the hypertrophic layer and also to the increase in the size of the individual cells; apparently the proliferative layer remained unaltered although it is possible that accelerated division had taken place but, because of the great rapidity of this division, could not be detected, but could have produced the moderate increase in the

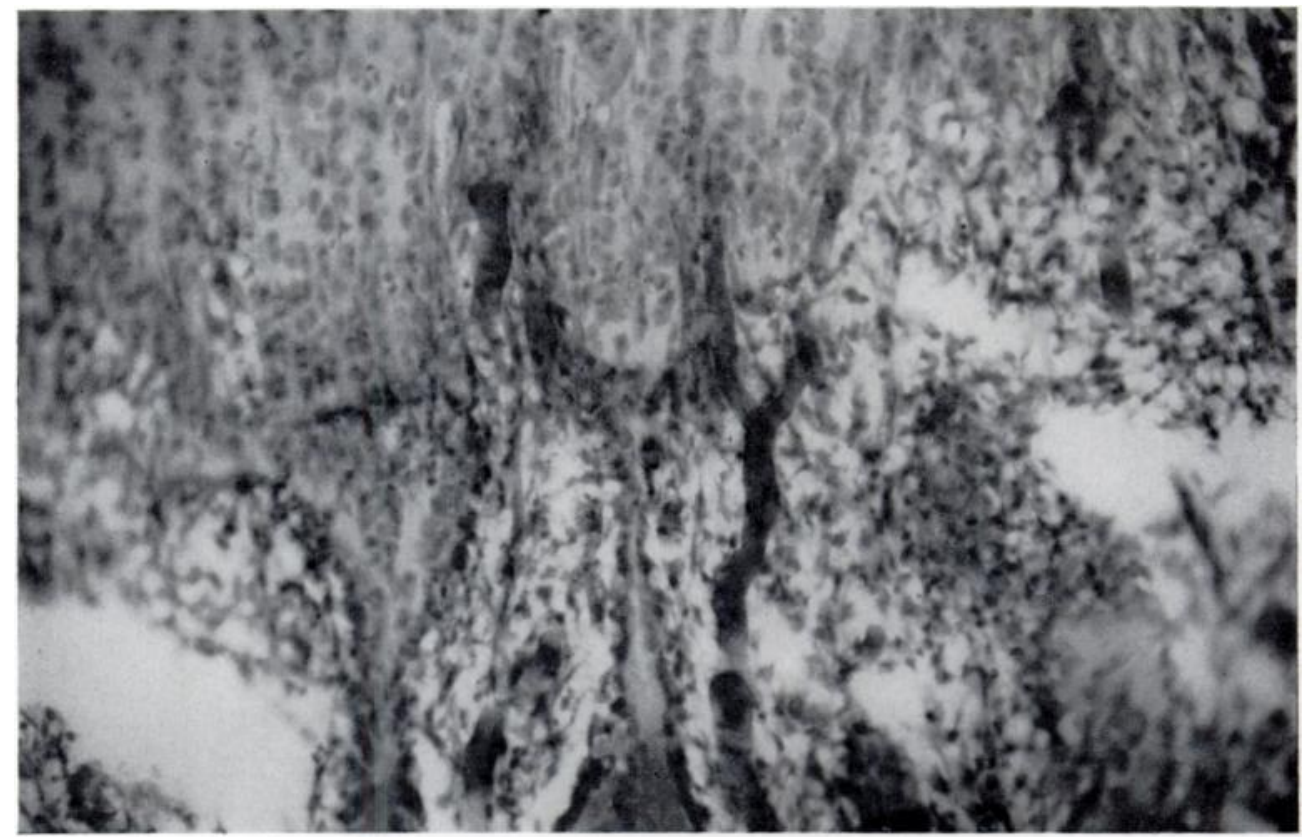

FIG. 5

Metaphysial vessels penetrating the epiphysial cartilage and laying down new bone (bottom centre of illustration) after a break had occurred at the epiphysial side of the growth cartilage. $(\times 75$.

number of hypertrophic cells. The widening of the growth cartilage was accompanied by a denser network of blood vessels in the region of the terminal bone plate and it was always more noticeable towards the periphery. The intercellular matrix took on a darker stain. These effects were transient and could not be seen after a few days. Occasionally patchy damage was detectable in the plate. The thick sections showed this to correspond exactly to the area of ischaemia. The upper cells of the growth plate, referred to in a preceding paper of this series (Trueta and Little 1960) as the germinal cells, showed metachromasia; also a varying number of cells appeared dead, leaving empty V-shaped spaces consisting of intercellular matrix or matrix interspersed with dead or dying cells (Fig. 2). This minor degree of damage appeared capable of repair by a bulging inwards of the surrounding columns, so that the gap became closed off. The columns in such plates appeared fewer and farther apart, and the cytoplasm of many cells was granular (Fig. 3). The matrix was less well stained, appearing pale in colour. 


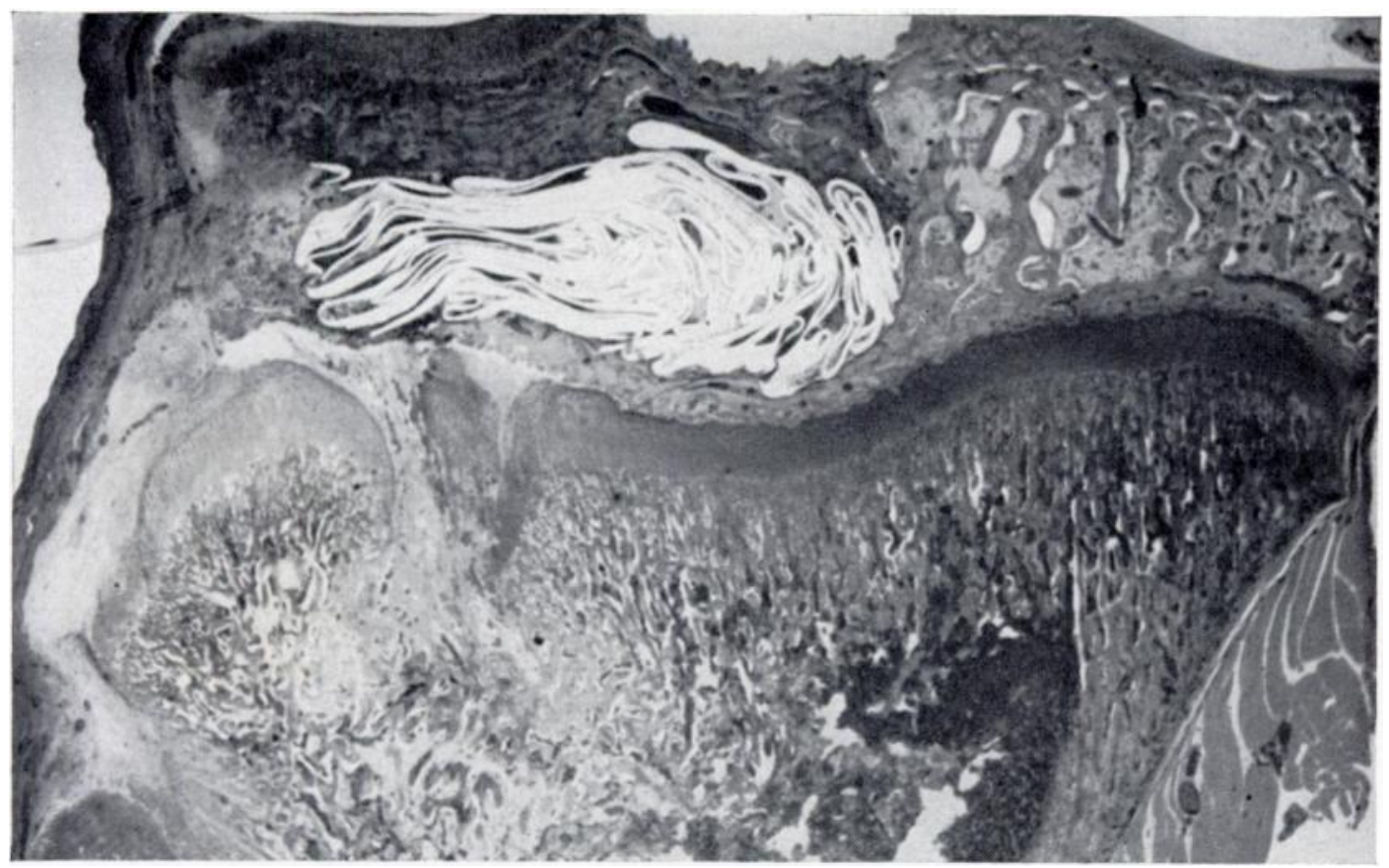

FIG. 6

Bridge across the epiphysial cartilage under an area of ischaemia caused by interruption of the epiphysial blood flow. $(\times 10$.

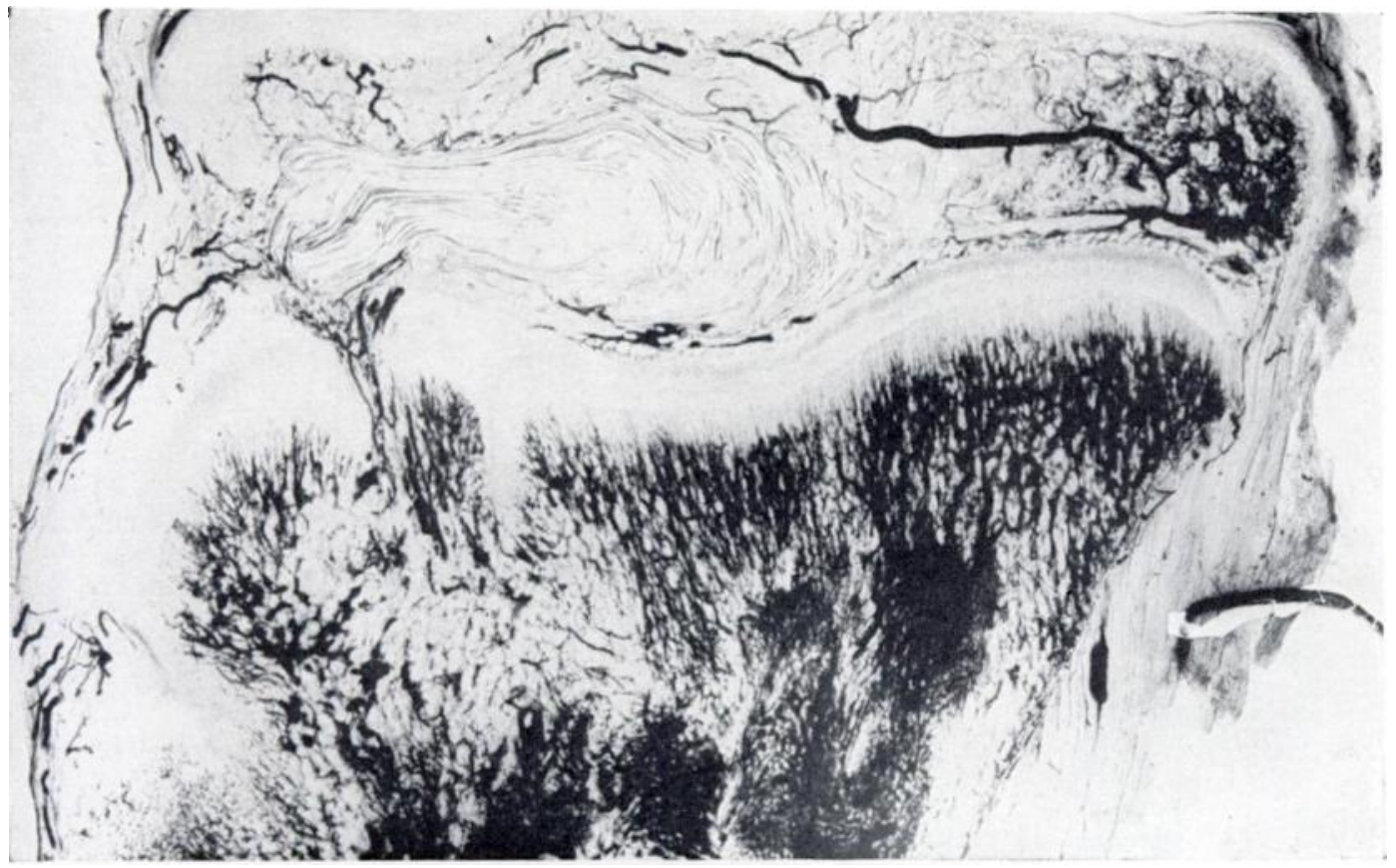

Fig. 7

The vascular bridge through the damaged growth cartilage. $(\times 10$.) 


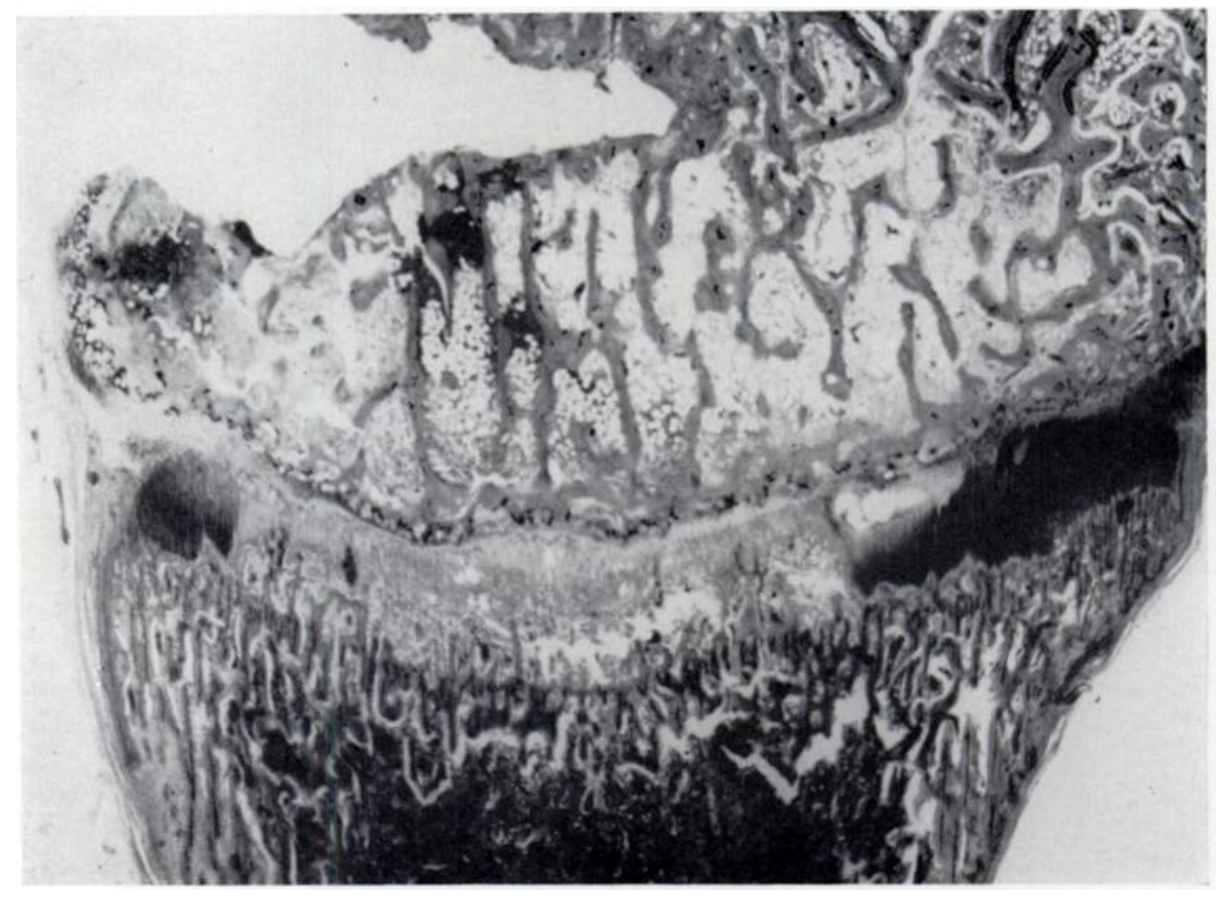

Fig. 8

Massive damage to growth cartilage caused by extensive damage to the epiphysial vessels. $(\times 17$.

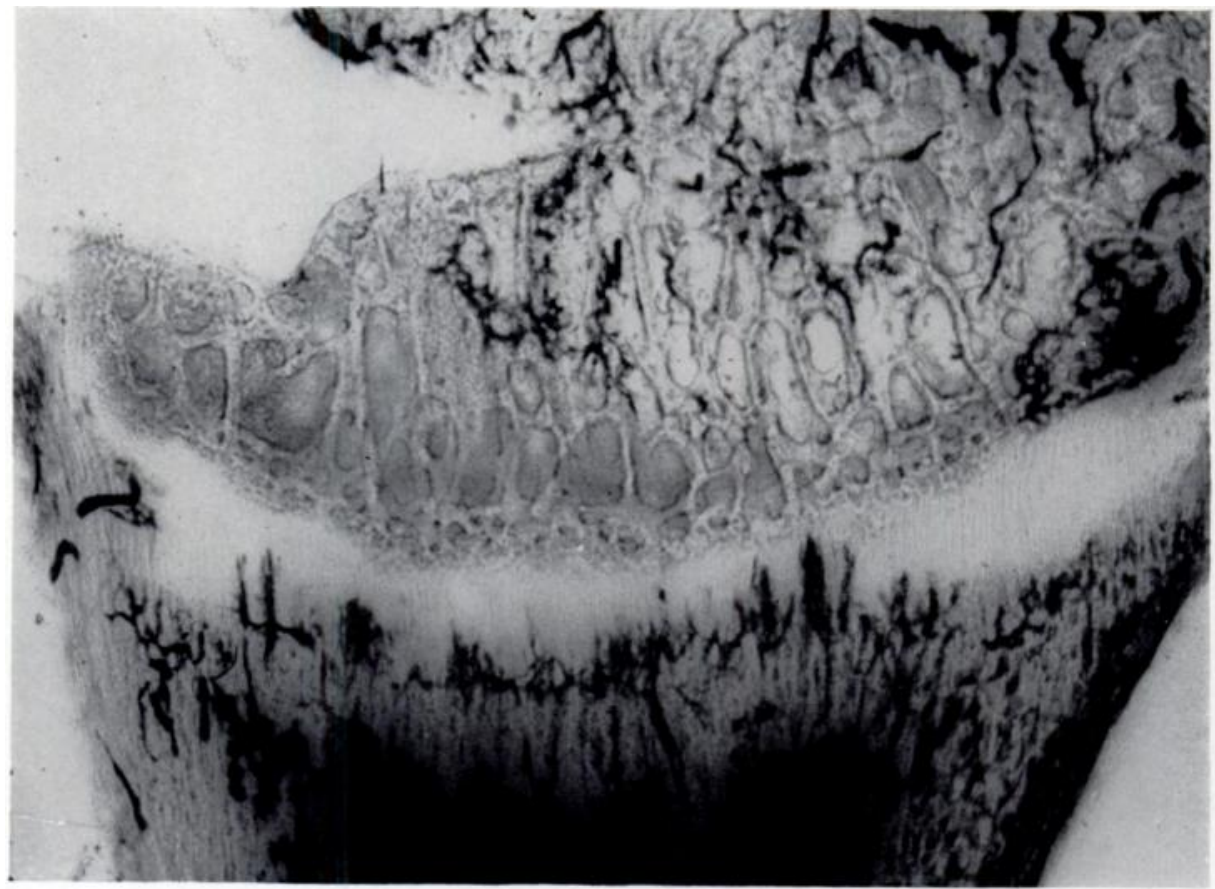

Fig. 9

Invasion of the damaged plate by metaphysial vessels. $(\times 11$. 
In areas where the damage involved a larger number of columns the gap was too wide to become sealed off. Growth continued normally in the surrounding columns and resulted in a pulling out of the infarcted portion of the plate (Fig. 4). Long, empty, or partly empty tubes of cartilaginous matrix stretched from the epiphysis to the metaphysis, and as no further calcification took place this area was left behind in the metaphysis. If this stretching out process went too far, eventually a break occurred, usually at the metaphysial end, and blood vessels invaded the area (Fig. 5). New bone was laid down along these capillaries (Figs. 6 and 7) so that the end-result was usually a bone bridge between metaphysis and epiphysis. The shortest interval for the whole sequence of events to develop after this type of injury was found to be eight days from the operation. In some of the experiments in which the blood flow was allowed to return, the invasion of the blood vessels took place from the epiphysial to the metaphysial side, but the ultimate result - a bone bridge between the epiphysis and metaphysis-was the same.

In massive lesions, where the main source of supply to the whole epiphysis was successfully cut off, rapid death of the whole of the central part of the plate occurred. The cells became metachromatic, losing their polarisation and their morphological characteristics, and the matrix became very pale throughout (Figs. 8 and 9). The area that suffered least was a limited rim of the peripheral part of the cartilage which receives its blood supply from vascular anastomosis around the plate. The capillaries from the metaphysial side invaded the devitalised area on a wide front and new bone was very soon laid down in their wake. Epiphysiodesis occurred within a short while, usually ten days from the vascular interruption, and growth ceased altogether.

Direct injury to the terminal bone plate-In certain instances the epiphysial bone plate and the upper part of the growth plate, which is so intimately connected to it, were injured at the time of operation. Irreparable damage always resulted and an invasion of the blood vessels took place early, followed by partial epiphysiodesis (Figs. 10 and 11). As the medial side of the tibia was always used and as this type of injury was most likely to affect the peripheral end of the plate, a varus deformity developed.

Lesions of this area were often complicated by damage to the perichondral ring as will be mentioned later.

\section{INTERRUPTION OF THE METAPHYSIAL BLOOD FLOW}

After division of the main vessels at the metaphysial side of the growth plate this increases appreciably in width within twenty-four hours, entirely as a result of the accumulation of the cells of the hypertrophic zone. As stated by Trueta and Morgan (1960) the number of cells in the columns of the upper tibial epiphysis of the rabbit at six weeks varies from thirty-five to fifty, according to the mitotic activity of the proliferative part of the columns at the time the count is made. An average increase of approximately ten to sixteen cells occurs every twenty-four hours in the area of total suppression of the metaphysial blood flow. After six days the average width of the growth cartilage is increased by sixty to ninety hypertrophic cells (Figs. 12 and 13) and after eight days it may be as much as 100 cells or more above the normal average. After this extraordinary increase in width of the growth plate, the rate of expansion becomes limited and the metaphysial end of the columns of cartilage cells, now placed deep into the metaphysis, press against each other often at a depth of six or eight cells before the end. This permanency of the hypertrophic cells is accompanied by a total lack of calcification of the intercolumnar matrix. A close investigation of the morphology of these hypertrophic cells shows that along the whole length of the columns they do not exhibit any appreciable modification, so that individually the hypertrophic cells at the top of this section resemble those placed at its end, often fifty or more cells apart (Fig. 14).

No degenerating cells are seen under these experimental conditions at the ends of the columns. The significance of this finding will be shown later.

vol. 42 B, No. 3, AUGUST 1960 


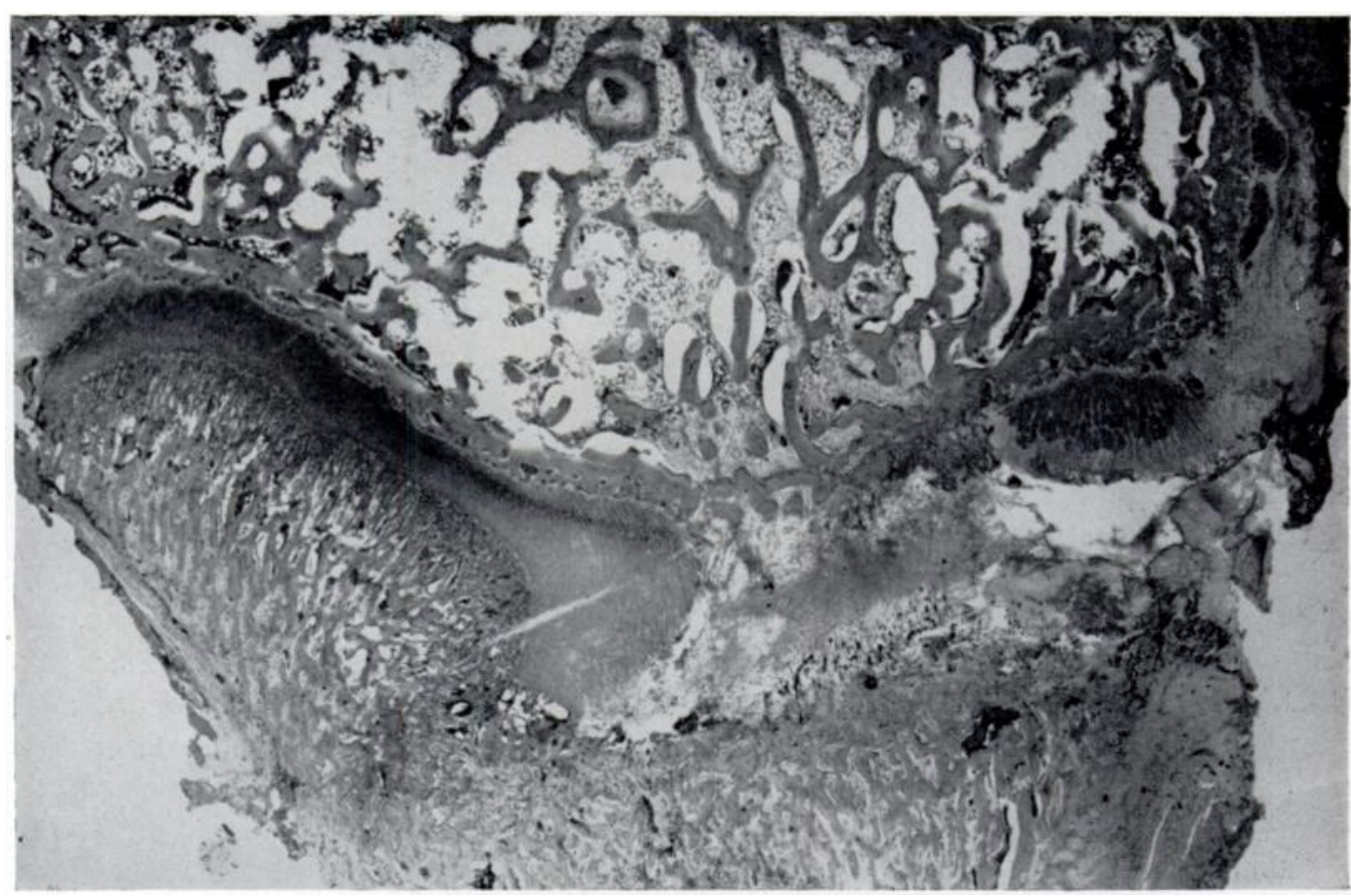

Fig. 10

Partial epiphysiodesis caused by direct damage to the epiphysial growth cartilage. $(\times 11$.

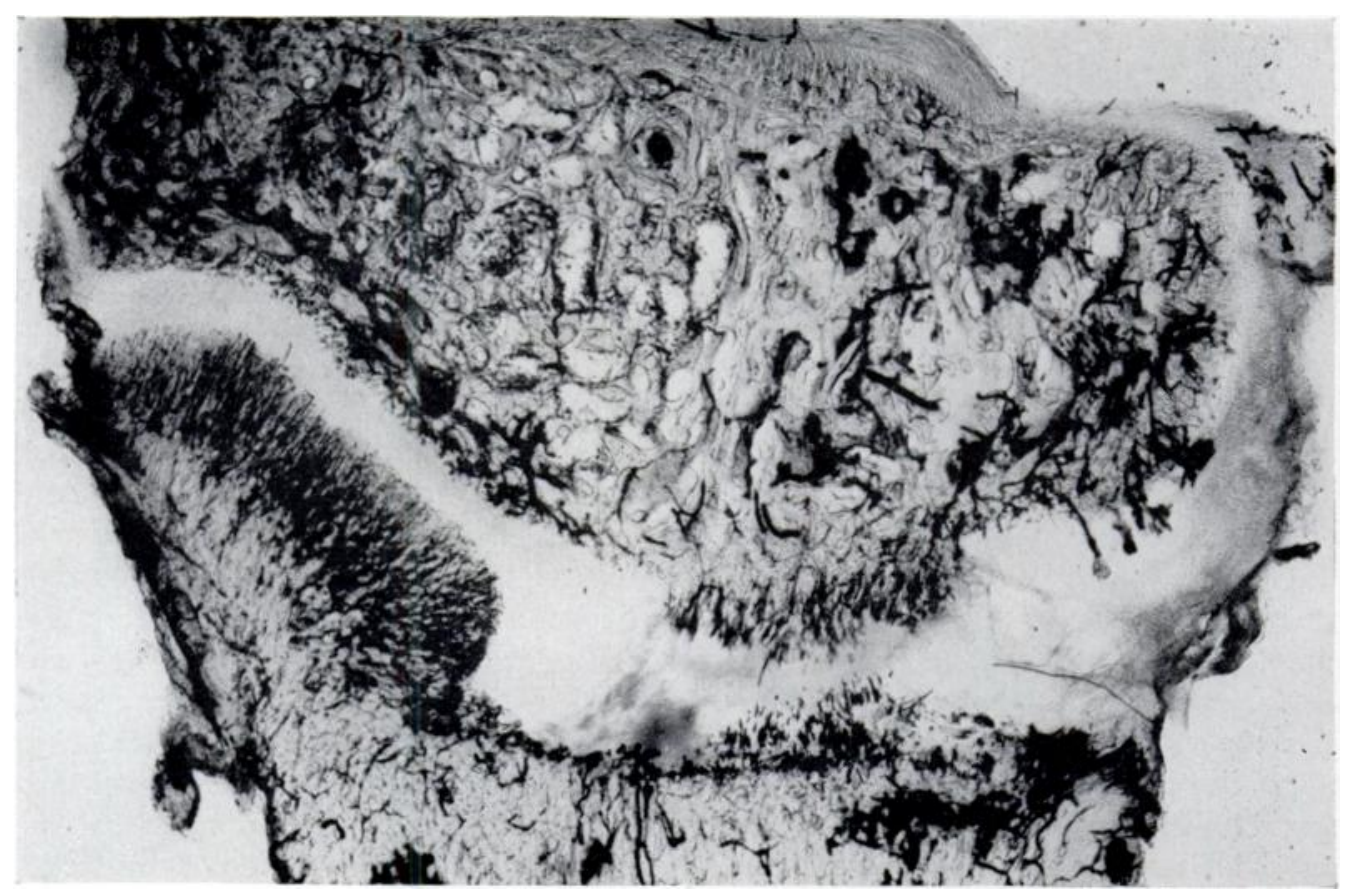

Fig. 11

Progress of the epiphysial and metaphysial vessels towards each other. $(\times 11$. 


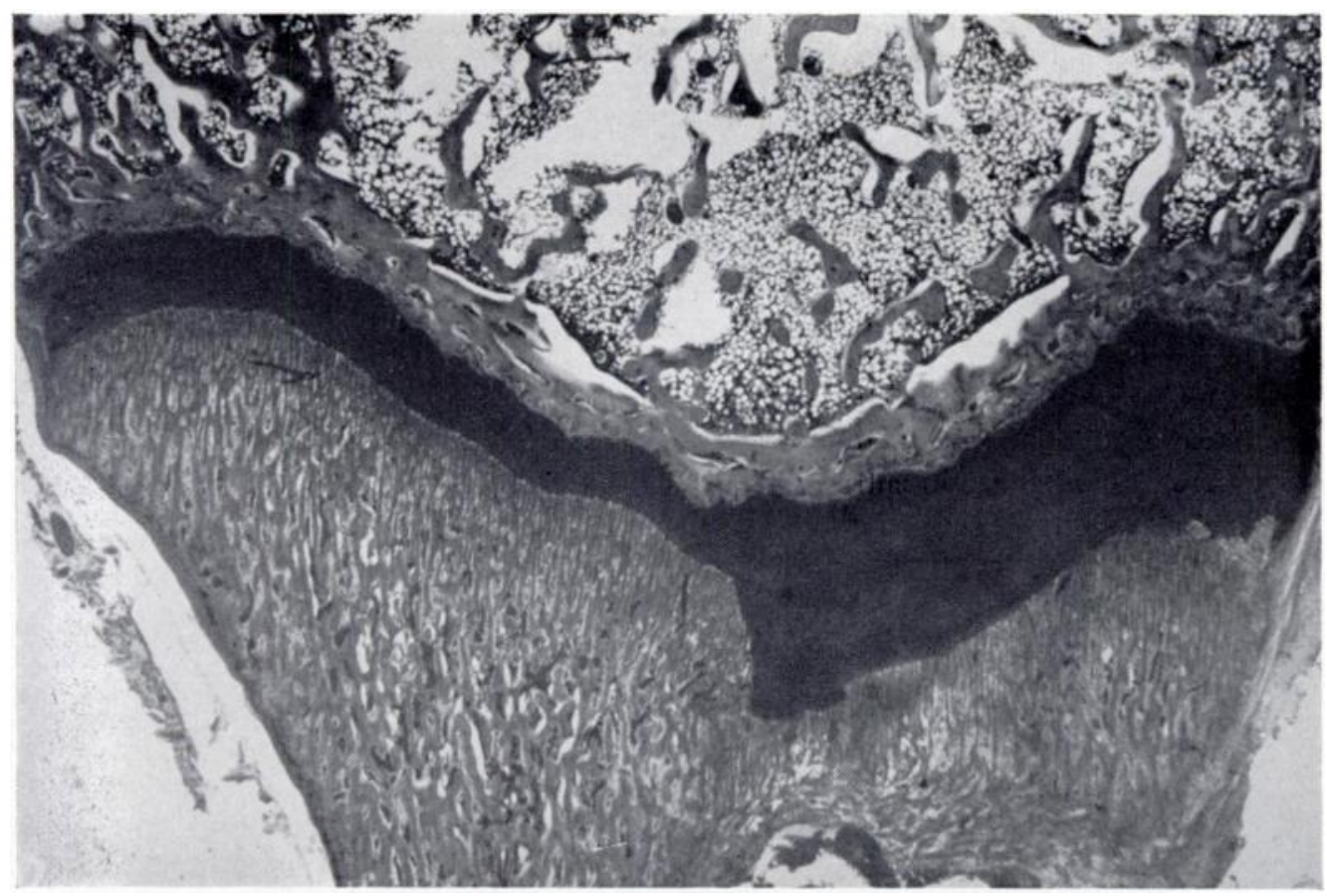

Fig. 12

Enlargement of epiphysial cartilage caused by the interruption of the blood flow through the metaphysial vessels under that part of the plate. $(\times 11$.)

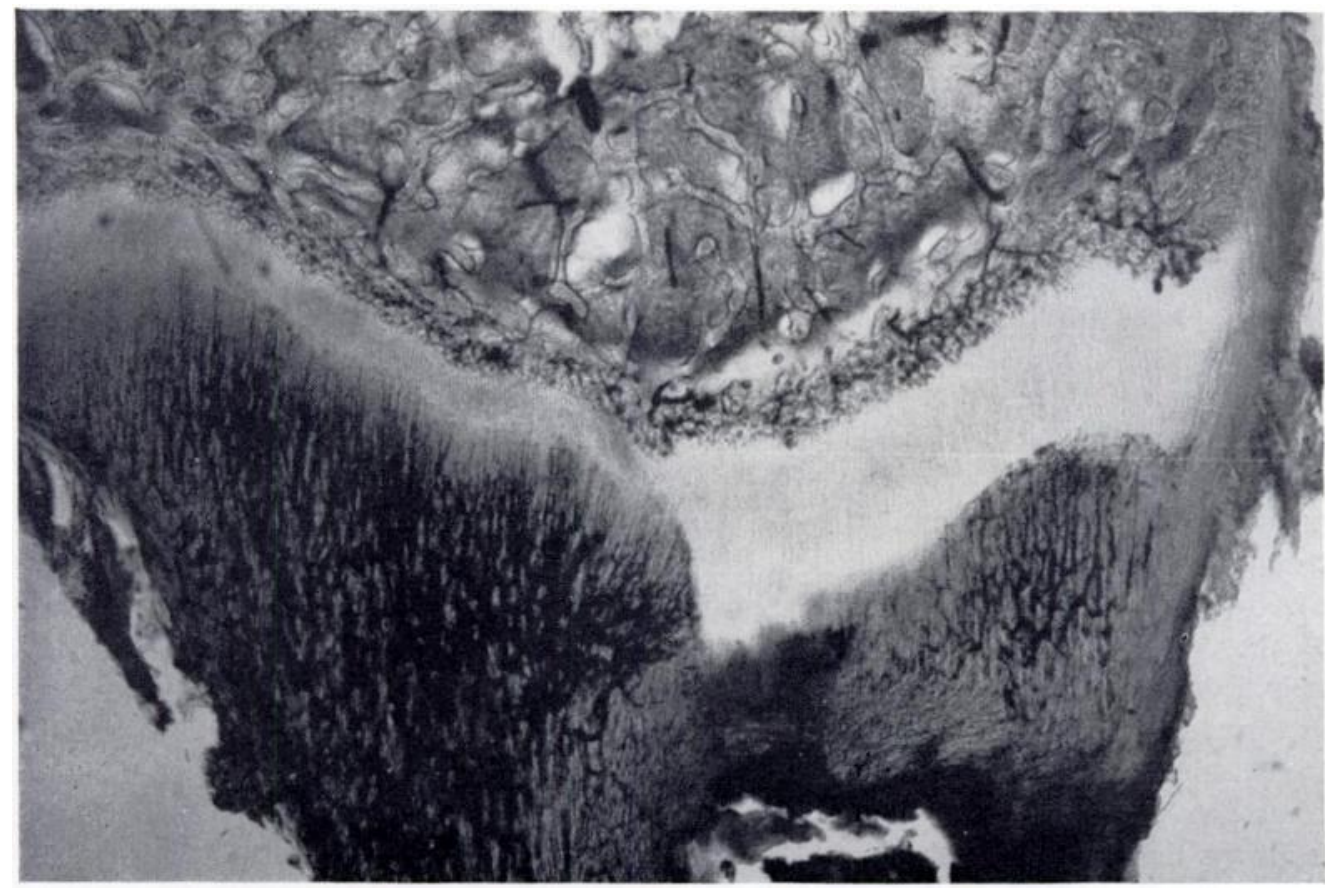

Fig. 13

Note the normal appearance of the epiphysial vessels and the lack of filling of the metaphysial vessels under the thick growth cartilage. $(\times 11$.)

VOL. 42 B, No. 3, AUGUST 1960 
It is of particular interest to make a comparative study of the part of the growth cartilage placed over a metaphysial area of ischaemia and that which corresponds to a metaphysial area of normal blood flow. It is as if all the activities so energetically engaged in the normal had been suspended, including calcification, preliminary ossification, bone reabsorption and final bone formation. Large zones of calcified cartilage and preliminary bone (Fig. 15) remain at a level in the metaphysis where, normally, remodelling is taking place (Fig. 16).

A somewhat surprising feature is the apparent

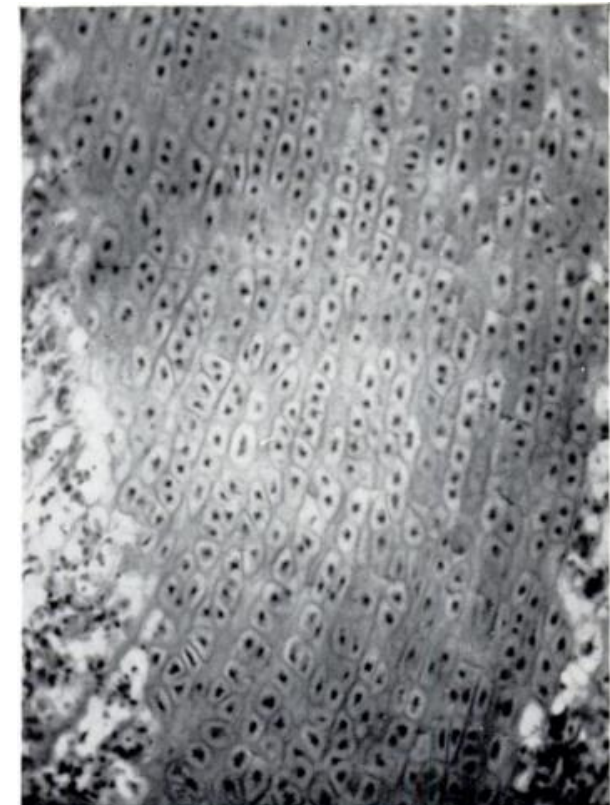

Fig. 14

Detail of a " tongue" of epiphysial cartilage showing the healthy hypertrophic cells with no empty columns at their sides, and the degenerating cells at the distal end of the columns. $(\times 45$.) survival of osteocytes in the metaphysial zone over the area of vascular suppression, suggesting that either the osteocytes, if they were dead. had no time to disintegrate or even change their staining characteristics, or else that sufficient blood flow still remained in the neighbourhood to provide the required transudates for their survival. Of these possibilities the latter seems the most likely, because in the injected specimens some of the perfusing mass was scattered along vessels in the supposedly avascular area. The reason for this was the integrity of a number of perforating metaphysial vessels which, as explained elsewhere (Trueta and Morgan 1960) provide some of the blood, while the main blood flow from the nutrient artery is interrupted by the polythene film. In general, osteoclasts were absent and were seen only in reduced numbers in the proximity of the new, or the few spared, blood vessels. Another constant finding was the lack of alkaline phosphatase concentration, characteristic of the hypertrophic cartilage cells near the zone of calcification.

Changes of the growth cartilage accompanying metaphysial vascular regeneration-Even without removal of the polythene film vascular proliferation from the perforating vessels invaded the ischaemic metaphysial area in less than twenty-four hours after the main blood flow had been blocked. Soon calcification and ossification proceeded along the now very elongated tubes surrounding the hypertrophic cells up to the normal level of calcification, with the usual eight or twelve hypertrophic cells left untouched, except that the last two or three were surrounded by calcified matrix, as in the normal (Fig. 17).

When the circulation was allowed to return freely by removal of the vascular block. the expanded growth plate calcified at a strikingly rapid rate from the periphery to the centre, each column starting at the farthest end in the metaphysis. The capillary loops entered at the bottom of the columns and in a few days travelled up-one loop to each column-to the level they would normally have reached had the vessels not been interrupted. New bone was laid down by the osteoblasts, appearing as a lining inside each tube. The trabeculae thus formed were thinner and more uniform than those of the control side and remodelling lagged behind. Alkaline phosphatase activity was increased and appeared to be related to the vascular progression. The last part of the growth cartilage to be calcified and ossified was always that in the centre, being the last to be reached by the incoming vessels. It often persisted as a long finger-like process of varying thickness and consisted of orderly columns of hypertrophied cells which on occasion numbered as many as 100 or more (Fig. 14). In thick sections a clear division between the old and the new blood vessels was seen, a division 


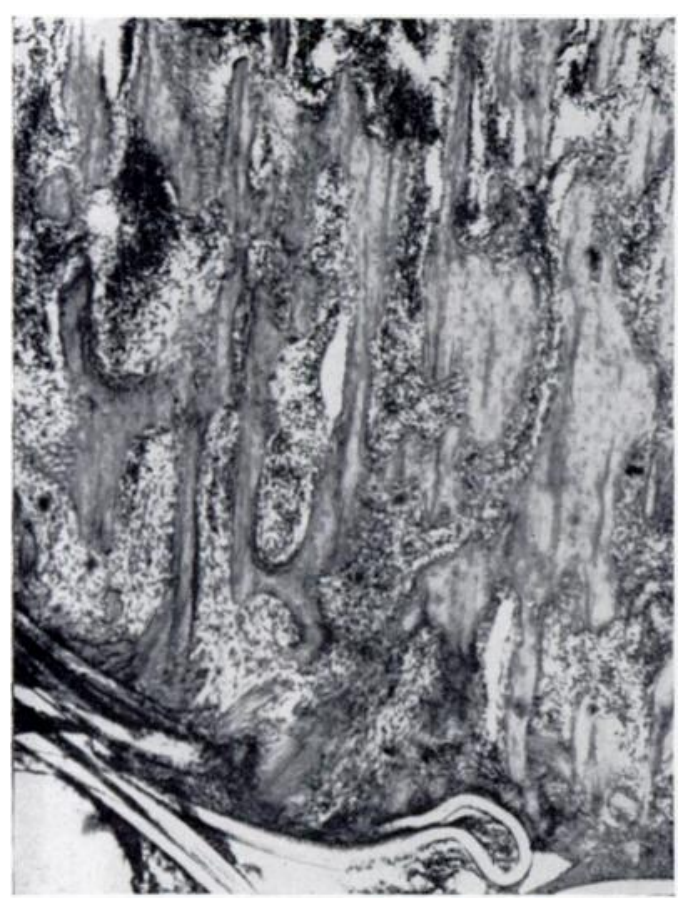

Fig. 15

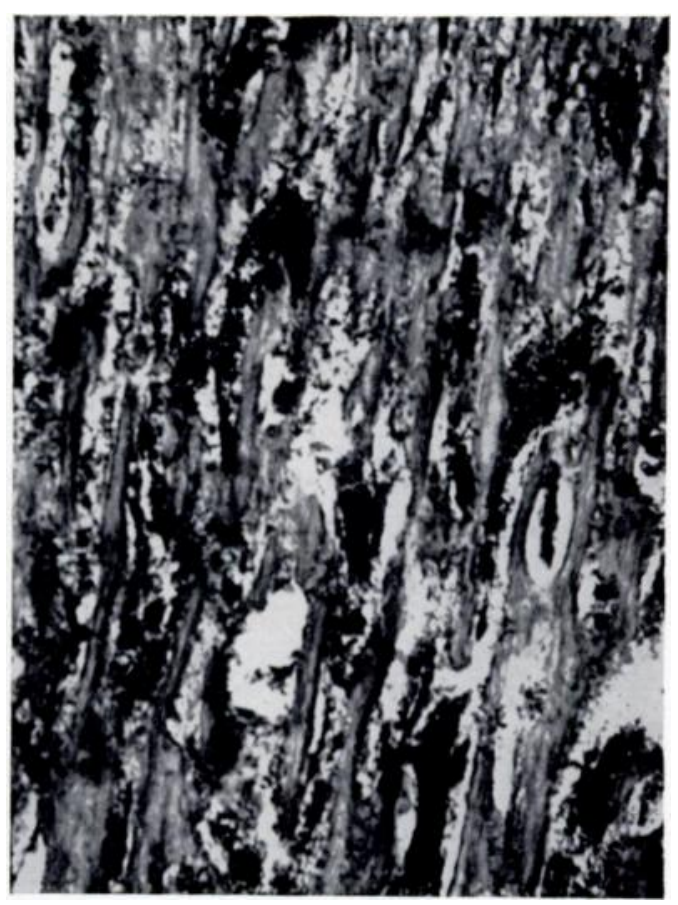

FIG. 16

Figure 15-Lack of remoulding of bone is seen above the polythene block, even if the osteocytes appear to be alive. Compare this with Figure 16. ( $\times 50$.) Figure 16-Advanced bone remoulding in the normal, at the same level in the bone as that of Figure 15. $(\times 55$.

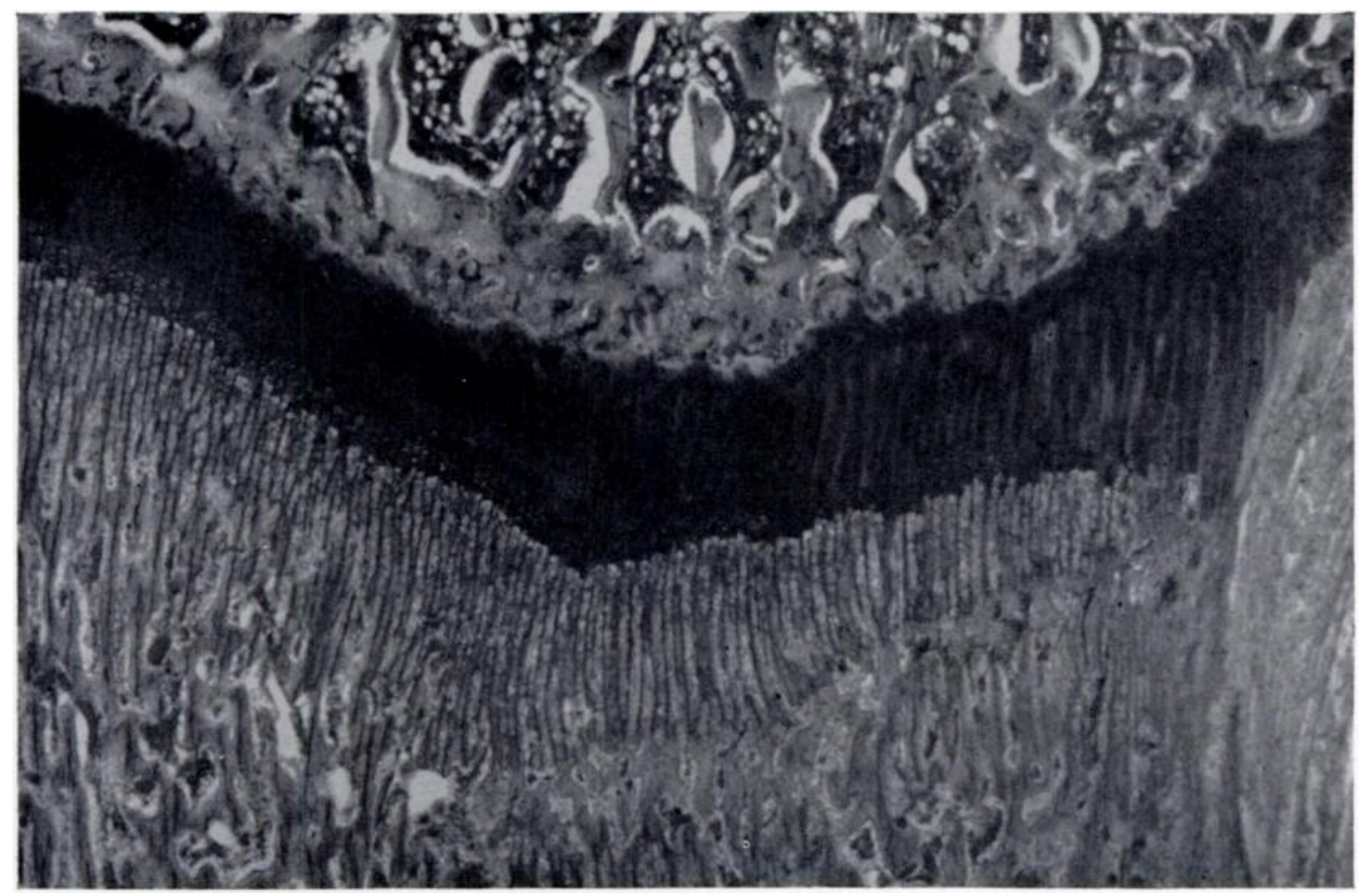

FIG. 17

After metaphysial revascularisation occurs the number of hypertrophic cells becomes normal. The recently calcified tubes are clearly shown by their straight course. $(\times 15$.

VOl. 42 B, No. 3, AUGUST 1960 
which exactly corresponded to the width of the finger-like process (Figs. 18 and 19). The vascular loops were always orientated in the direction of the columns, for, as has been stressed above, they only gained entrance to each column from its distal end. The widened growth cartilage did not tend, as a rule, to be broken up into islands of columns and cells but. on the contrary, calcification and ossification always proceeded very regularly. Occasionally, however, in the animals with the main metaphysial vessels obstructed for eight days or more an impenetrable barrier became established round the columns and their distal ends remained firmly closed. The vascular loops in these cases short-circuited the barrier by getting in between the long but normal-looking columns and those which appeared disorganised and unhealthy, and proceeded to lay down bone by the normal mechanism of vascular invasion of the hypertrophic cartilage.

In some instances if the central part of the epiphysial cartilage remained unossified for too long, permanent damage was caused by its tendency to get peeled off from the terminal bone plate, covering it at its epiphysial side. Thus a severe lesion of the germinal and proliferative cells was caused in breaking these away from their natural surroundings, particularly the epiphysial vessels; they degenerated and soon were invaded by new epiphysial vessels which, by progressing towards the metaphysis, ended by establishing connections with the metaphysial vessels (Figs. 20 and 21). New bone was laid down and soon a central epiphysiodesis was established.

In the diaphysis the site of operation was always visible by its increased bone density; and its progress towards the shaft depended on whether or not a bony bridge had been established across the plate.

Damage to the perichondral ring-The operation occasionally damaged the perichondral ring of the ossification groove (Lacroix 1951) and a large chondroma or osteochondroma resulted. It often spread down the metaphysis, and vessels from this region grew into it (Figs. 22 and 23). Normal moulding with organised growth did not take place and osteoclasts were absent from this region. There was a disorderly vascular invasion of the mass of cartilage cells, and bone was laid down as in the cartilage anlage before the growth cartilage is arranged in parallel columns of cells (Fig. 24). The bone trabeculae were therefore irregular and the orderly laying down of bone characteristic of metaphysial bone formation was totally absent.

Bone bridging and partial epiphysiodesis-When a bone bridge became established between epiphysis and metaphysis it resulted in growth disturbances which followed a regular pattern according to the size and location of the bone bridge. Superimposition of thin and thick sections showed that a bone bridge was always immediately preceded by a vascular invasion across the area of damaged cartilage. If the two circulations could be kept apart no bridging occurred.

The effect upon growth after the establishment of a bone bridge was of interest and will be analysed elsewhere. It will suffice to mention that bone bridges of equivalent sizes caused greater deformities if placed at the periphery than at the centre of the growth plate, particularly if the perichondral ring was seriously affected, as in the experiments reported by Trueta and Trías (1957).

\section{DISCUSSION}

The results of this investigation throw light on the respective role of each of the two systems of vessels (epiphysial and metaphysial) carrying the blood to the epiphysial cartilage. The technique used allowed the production of isolated disturbance to either of the two systems and offered the opportunity of studying the part each plays in the process of growth. It was established in a preceding work (Trueta and Morgan 1960) that the metabolic requirements of the reproductive cells of the epiphysial cartilage, and perhaps of all the cells in the columns, are supplied through the epiphysial vessels described as forming a ceiling under the roof of the bone plate. There is very little doubt that these vessels are responsible for carrying the blood to the 


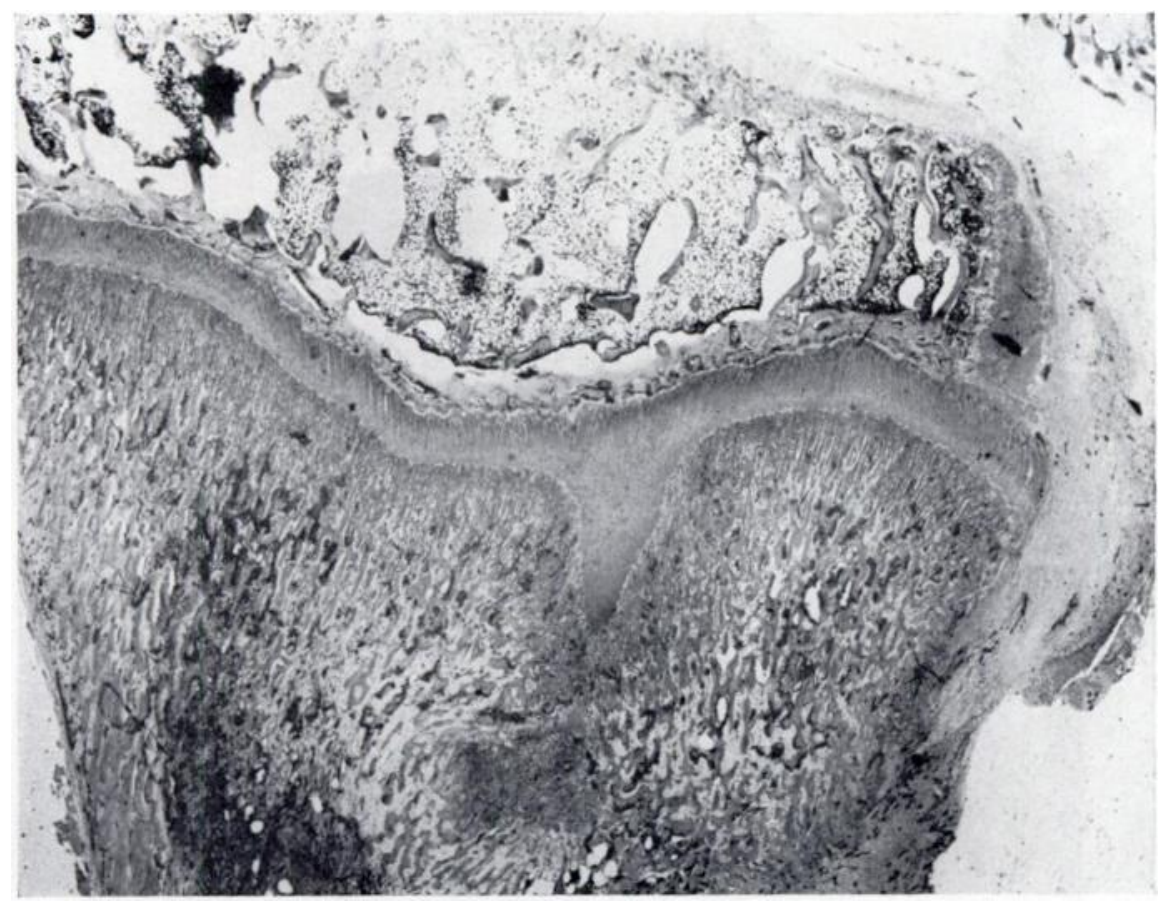

FIG. 18

Finger-like process left after metaphysial vascular regeneration near the centre of the growth cartilage. $(\times 10$.

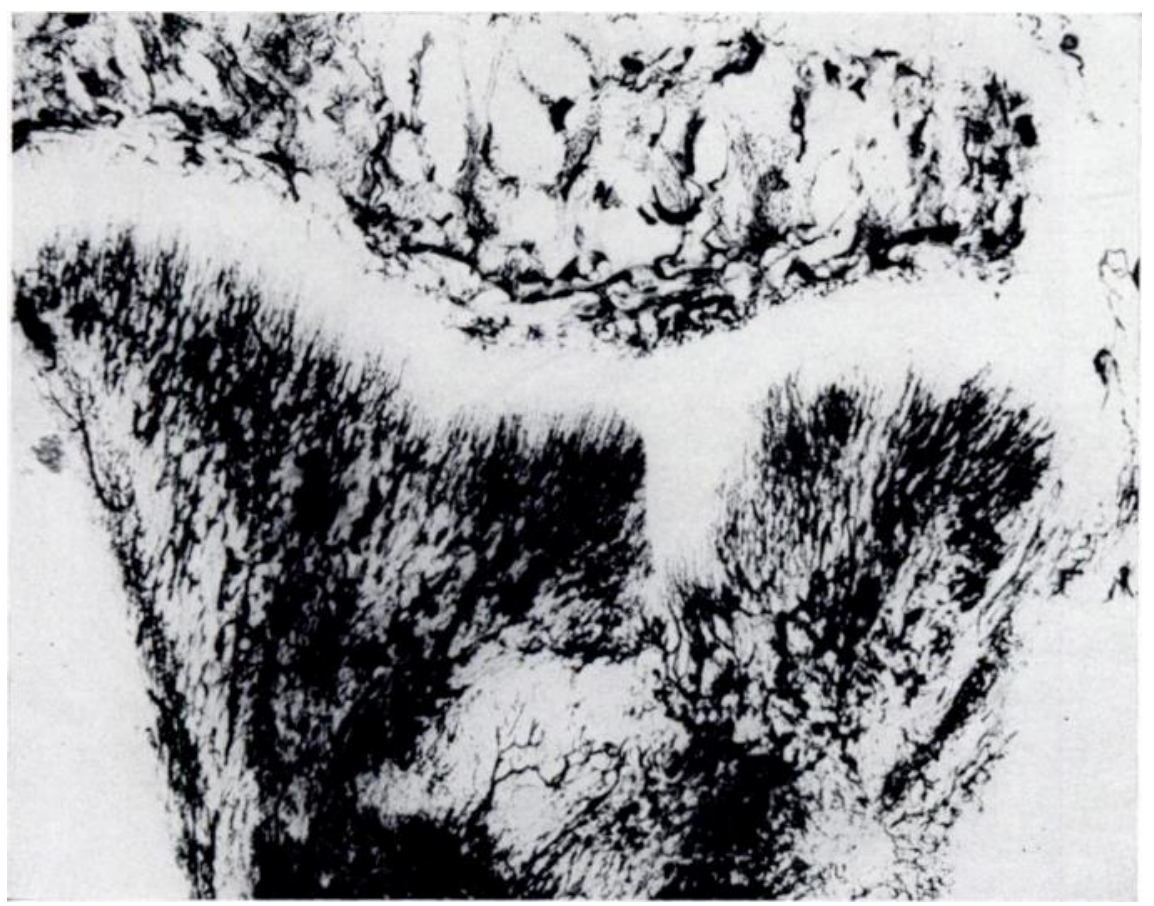

FiG. 19

The vascular penetration of these columns of hypertrophic cells, which always starts from the distal end, has not yet taken place. $(\times 10$. 


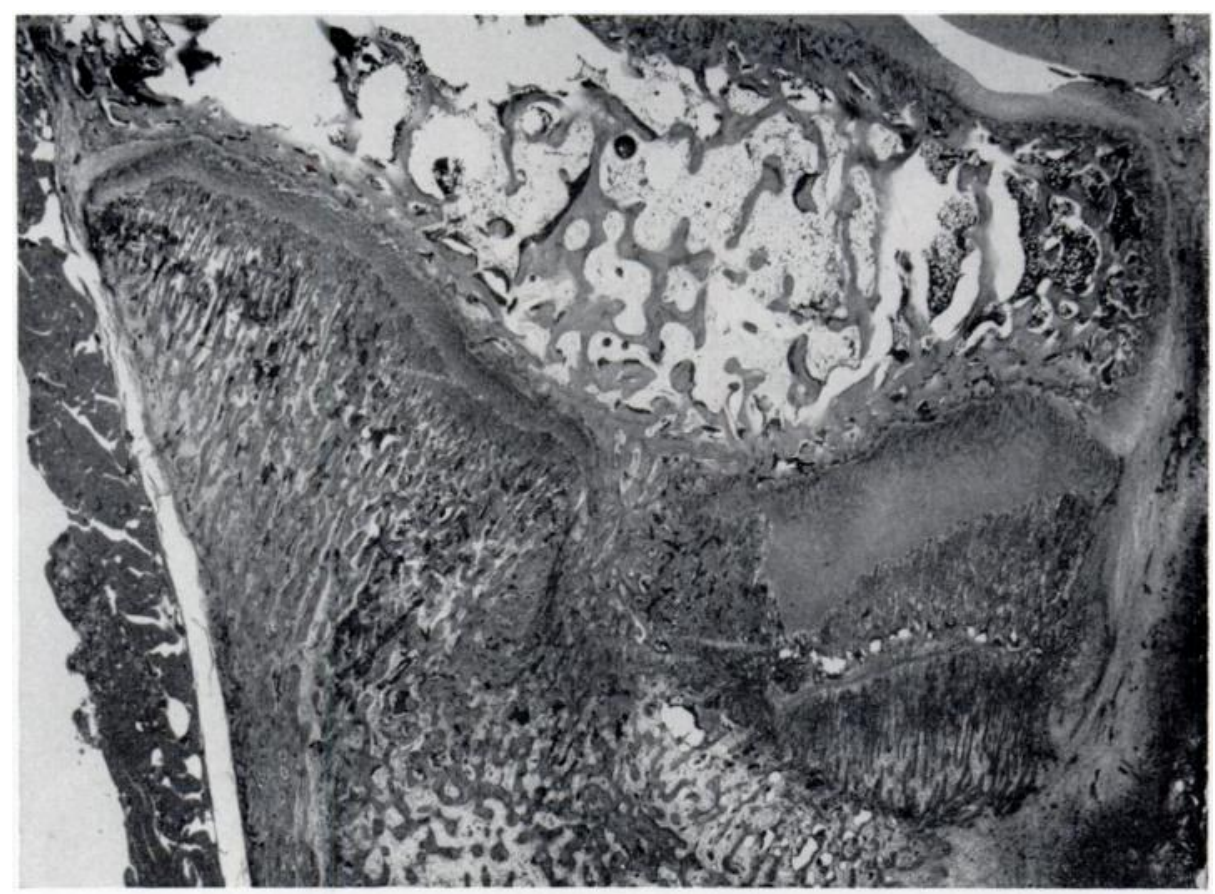

Fig. 20

After severe damage to the growth plate there was a tendency for it to peel off from the terminal bone plate if the central part of the growth cartilage remained unossified too long. $(\times 11$.

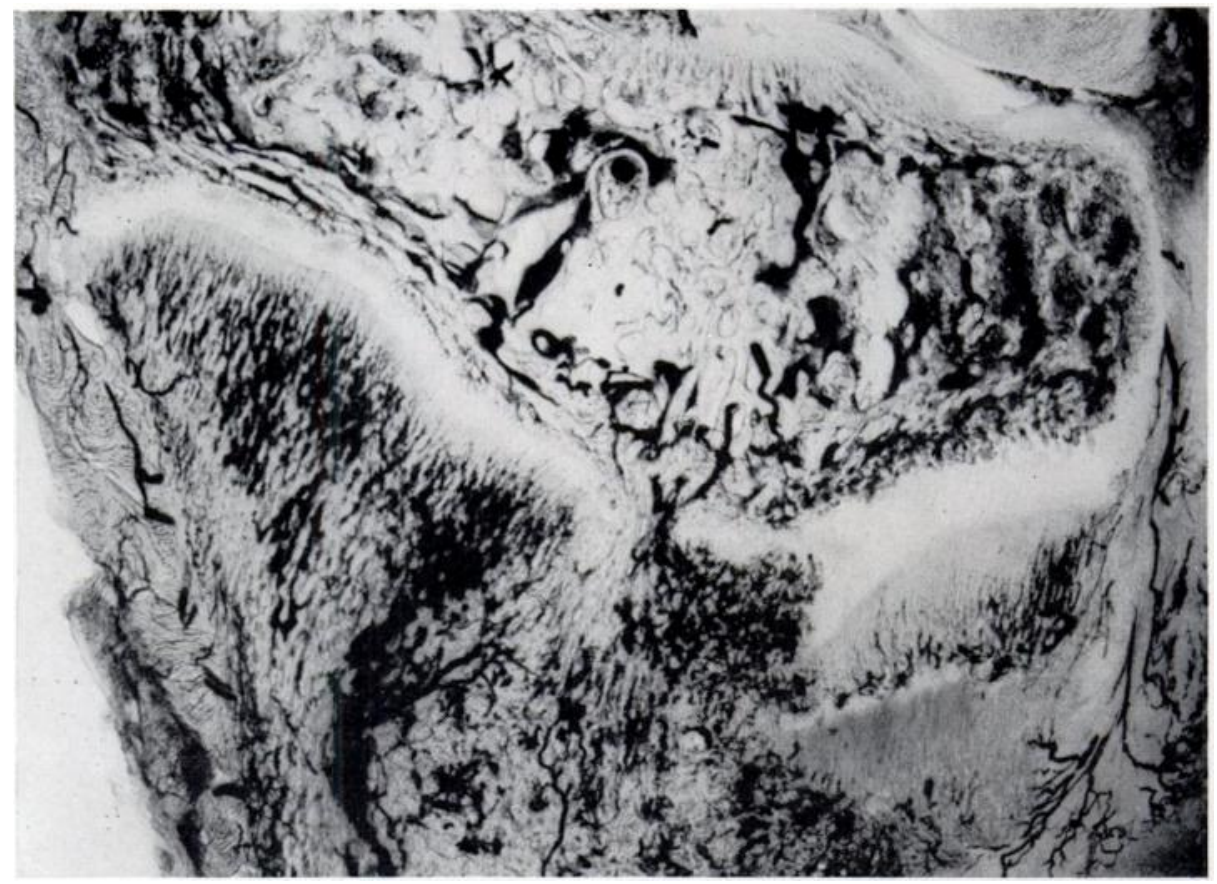

Fig. 21

The vascular invasion of the bridge. $(\times 11$. 


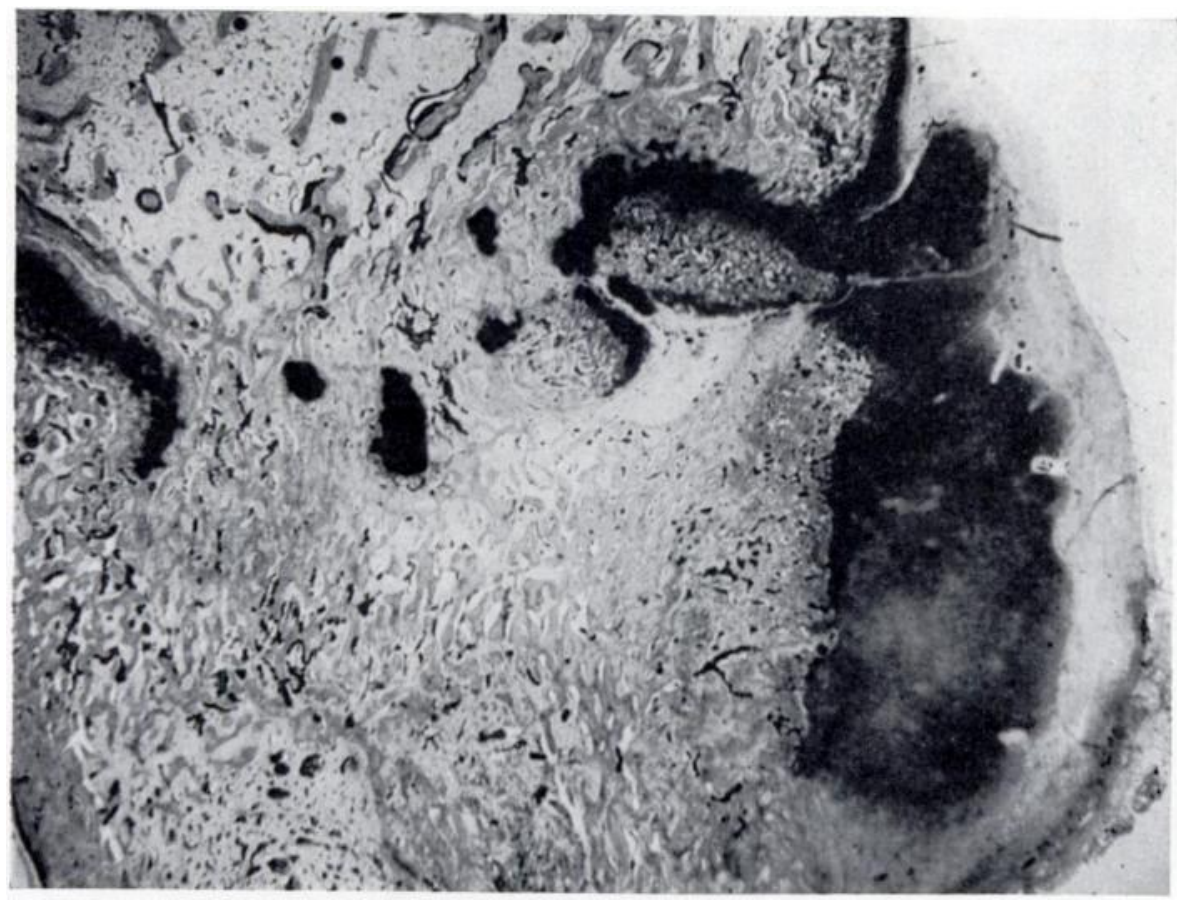

Fig. 22

Damage to the perichondral ring disorganised the growth cartilage and a large " chondroma " resulted. $(\times 12$.

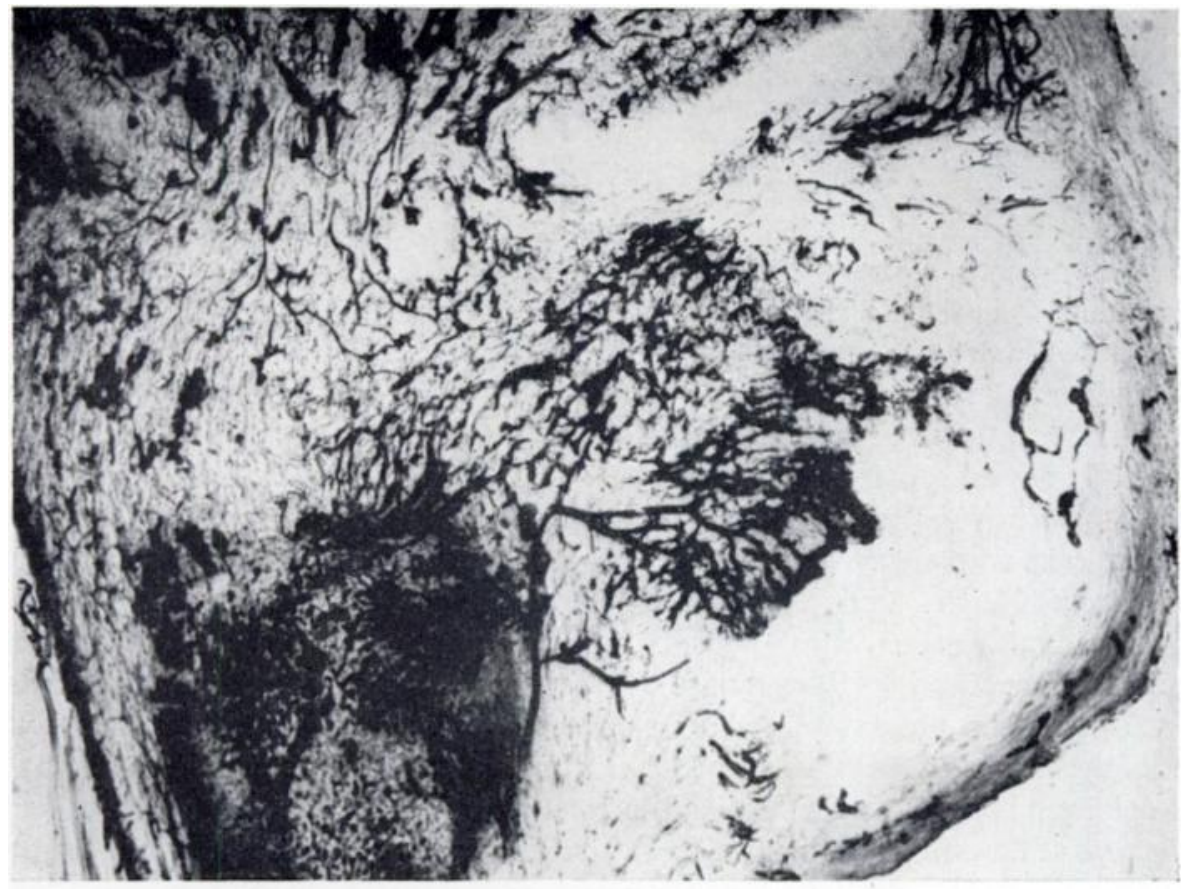

FIG. 23

Metaphysial vessels penetrating the " chondroma" from its deepest part. $(\times 35$.

VOL. 42 B, No. 3, AUGUST 1960

L 
cells actively engaged in reproduction. The fact that any extensive damage to the epiphysial vessels causes irreparable lesions to the columns of cartilage cells does not exclude the possibility that temporary ischaemia may be followed by an augmented vascularity responsible for causing an increase in the width of the growth cartilage. It is interesting that this is due to an increase in size of the hypertrophic cells and in their number, which in the absence of vascular

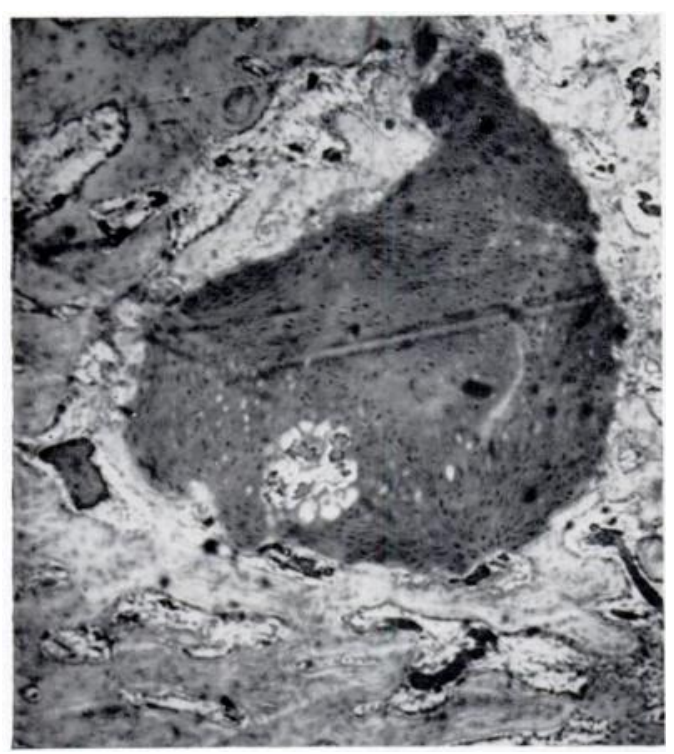

FIG. 24

FIGS. 24 AND 25

Figure 24-Isolated "chondroma" caused by damage to the perichondral ring, being invaded by vessels in a disorderly way. $(\times 45$.) Figure $25-$ Enormously long columns of hypertrophic cartilage cells caused by experimental rickets in the rat. Note the resemblance to the enlargement of the growth cartilage produced by metaphysial ischaemia shown in Figure 14. $(\times 45$.)

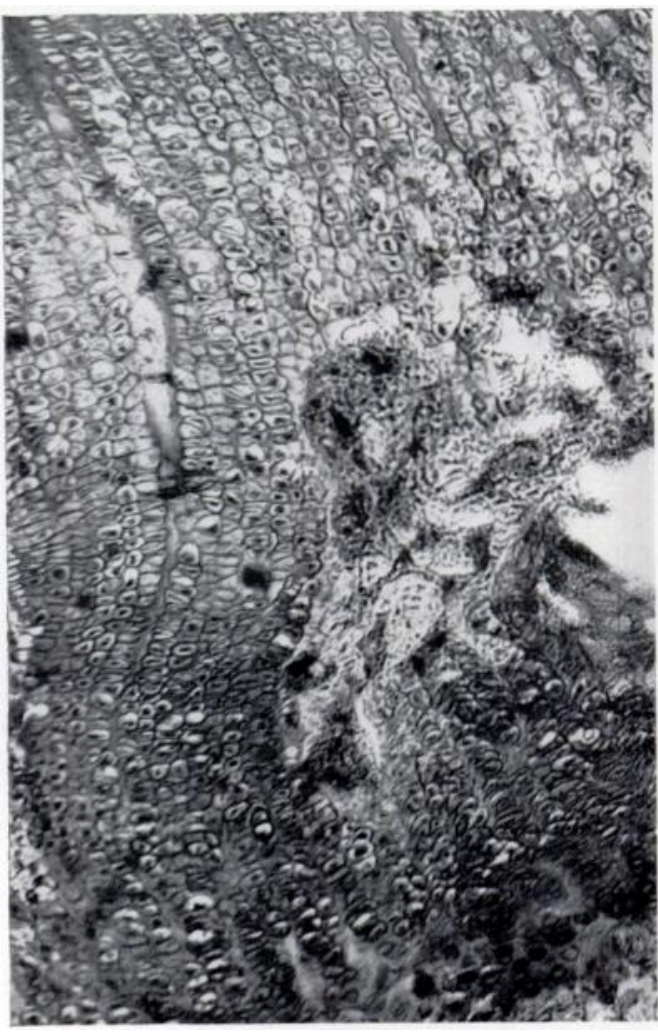

FIG. 25

impairment at the metaphysial side of the plate suggests an accelerated cell division at the proliferative segment of the column. The existence of the tubes empty of proliferative and hypertrophic cells in the middle of normal columns suggests that death of individual columns may be compatible with normal or nearly normal growth.

Once the responsibility of the epiphysial vessels for nourishing the epiphysial cartilage is established, it is interesting to consider the depth to which the transudates from these vessels may reach. In a normal epiphysial growth cartilage the proliferative cells begin to enlarge. and to become hypertrophic by the middle of its width. These new cells acquire the characteristics of the giant cells with vacuoles, oedema, etc. But no further changes occur to them as they become progressively separated from the epiphysial source of nutrition until they reach the area of matrix calcification. In the normal average cartilage this occurs from eight to twelve cells from the first showing hypertrophy. Only two or three cells farther down, degeneration sets in and, with the proximity of the metaphysial vascular loops, the final removal of the remains of the cartilage cells takes place. The nutritional dependence of all the cells in the tubes on the epiphysial vessels is further shown by the disorganisation and death which occurs when the tops of the columns are pushed away from their normal position after the suppression of the main metaphysial blood flow, which is responsible for the growth cartilage enlargement.

The main role of the metaphysial vessels-carrying calcium and vitamin D in the serum and phosphates in the red corpuscles-was seen to be the calcification of the matrix, the 
removal of the degenerate cells and the laying down of lamellar bone along the inner side of the empty tubes. That the blood carried by these vessels is of no nutritional importance to the hypertrophic cells was shown by their healthy appearance once the majority of the metaphysial vessels were divided; with this no further calcification of the matrix occurred and the hypertrophic cells took a new lease of life, which suggests that the primary cause of their death is the presence of the metaphysial vessels-with normal blood-in their neighbourhood. Alkaline phosphatase activity was also suspended by the arrest of the metaphysial blood flow, suggesting that with its production the hypertrophic cartilage cells must be on their way towards " degeneration."

The long columns of hypertrophic cells resembled those which are characteristic of rickets (Fig. 25), thus pointing out that that which keeps the hypertrophic cells alive is not the absence of the metaphysial vessels but the absence of calcification. The vascular pattern in rickets will be studied elsewhere. Provided that-as in these experiments-there was no deprivation of vitamins $A$ and $D$, calcification to the normal level occurred with extraordinary rapidity shortly after revascularisation was allowed. The columns of hypertrophic cells disintegrate and the tubes round them calcify up to the normal level, which suggests that vascular invasion depends on calcification-which will weaken the cell first-and that calcification can only occur close to a vessel which carries the appropriate blood, and when the matrix is ready to calcify.

The method of metaphysial vascular suppression has allowed the study of the rate of new cellular additions in the growth cartilage in twenty-four hours. The evidence suggests that, in the rabbit's tibia, from ten to sixteen new cells are added to each column in a day. That would mean about one-third to half of a millimetre in growth in length in twenty-four hours as an average, which is near the findings obtained in this centre by the measurement of growth on fine grain radiographs.

\section{CONCLUSIONS}

In this work the role of the blood vessels surrounding the epiphysial growth plate has been studied. The nutritional dependence of the proliferative cells on the epiphysial vessels has been established whereas the metaphysial vessels were seen to take part in calcification and ossification at the metaphysis.

As it does not seem likely that the blood circulating in the two systems of vessels had a different constitution, particularly in hormones and vitamins, it seems permissible to assume that it is the characteristics, particularly in shape and number, of such vessels that make growth the orderly process it is, with the repeated birth of a cell at the top of a column and burial at the bottom end. But, despite this undeniable role of the vessels, growth depends on the ability of the cartilage cell to form a matrix which, in due course, will be avid for apatite crystals.

Our thanks are due to Dr K. Little for her constructive criticism during the preparation of this paper and to Mr D. W. Charles and Miss M. Litchfield for their technical assistance.

\section{REFERENCES}

Lacroix, P. (1951): The Organization of Bones. London: J. \& A. Churchill Ltd.

Trueta, J., and Little, K. (1960): The Vascular Contribution to Osteogenesis: II. Studies with the Electron Microscope. Journal of Bone and Joint Surgery, 42-B, 367.

Trueta, J., and Morgan, J. D. (1960): The Vascular Contribution to Osteogenesis: I. Studies by the Injection Method. Journal of Bone and Joint Surgery, 42-B, 97.

Trueta, J., and Trías, A. (1957): La etiología y patogenia del húmero-varo. Revista de Ortopedia y Traumatologia (Edición Latino Americana), 2. 107. 